\title{
A CULTURA E A EXTENSÃO UNIVERSITÁRIA ATRAVÉS DA ORQUESTRA SINFÔNICA DA UNIVERSIDADE DE SÃO PAULO
}

\author{
CULTURE AND UNIVERSITY EXTENSION THROUGH THE SYMPHONIC \\ ORCHESTRA OF THE UNIVERSITY OF SÃO PAULO
}

${ }^{*}$ Edson Leite

\section{RESUMO}

O objetivo deste trabalho é demonstrar a importância da Orquestra Sinfônica da Universidade de São Paulo (OSUSP) no contexto da cultura e extensão a partir do modelo consistente em uma orquestra altamente qualificada, formada por profissionais, com independência dos departamentos de Música da Universidade, mas ligada à Pró-Reitoria de Cultura e Extensão Universitária. Este trabalho, baseado na revisão bibliográfica, apresenta um exame sumário da formação das primeiras sinfônicas no mundo e no Brasil, do papel do regente, dos músicos, dos modelos de orquestras universitárias e da OSUSP como ferramenta cultural a serviço da extensão universitária.

Palavras-chave: Orquestra. Universidade. Ação cultural.

\begin{abstract}
This paper aims to demonstrate the importance of Symphonic Orchestra of the University of São Paulo (Orquestra Sinfônica da Universidade de São Paulo - OSUSP) in the context of culture and university extension starting from the consistent model of a highly skilled Orchestra, composed by professionals, with independence of the Music departments of the university, but connected to the Office of the Provost of Culture and Extension. This paper, based on the literature review, presents a cursory review of the formation of the first symphonics in the world and in Brazil, from the role of regents, musicians, university orchestras models and OSUSP as a cultural tool in service of the university extension.
\end{abstract}

Key words: Orchestra. University. Cultural action.

* Professor titular da Escola de Artes, Ciências e Humanidades da Universidade de São Paulo (EACH-USP) e do Programa de Pós-Graduação Interunidades em Estética e História da Arte (PGEHA) da USP, vice-diretor da EAGH-USP e diretor da Orquestra Sinfônica da Universidade de São Paulo (OSUSP) - R. da Praça do Relógio, IO9 - Cidade Universitária - São Paulo - SP - 05508-050-e-mail: edsonleite@usp.br. 


\section{INTRODUÇÃO}

A universidade é um espaço privilegiado para a compreensão dos grandes valores do saber, para o estímulo da criatividade, inovação e transmissão do conhecimento. Gabe a ela promover a preservação do patrimônio cultural, especialmente das manifestações da cultura popular e erudita, estimulando a reflexão, a crítica e a formulação de estratégias e políticas públicas na área da cultura para a valorização da pluralidade, do pensamento diverso e para a formação de valores éticos e culturais. Nesse cenário, enquadram-se a realização de concertos, a formação de corais e orquestras e a administração e manutenção de teatros e salas para a realização de eventos artísticos.

A noção de educação universal emana da própria ideia de universidade de Newman, o qual considerava que nesta instituição - encarada como um lugar privilegiado do saber universal - deveriam existir todos os ramos do saber, pois embora os estudantes não tenham possibilidade de abarcar todas as disciplinas que lhes estão disponíveis, beneficiam do convívio com os mestres que encarnam o círculo dos conhecimentos. Com efeito, os mestres, eles próprios peritos e defensores de seus domínios científicos, têm de acordar em conjunto as relações e eventuais contradições; o estudante só tem a ganhar em 'habitar' neste meio rico de tradição intelectual, independente de qualquer mestre em particular que o oriente, mesmo que, como é natural, se consagre apenas a algumas das disciplinas do amplo conjunto oferecido, escolha, aliás, que em princípio lhe pertence. [6]

Segundo Cristovam Buarque [4], com as atividades de extensão a universidade pode descobrir o mundo e somente com estas atividades o mundo poderá descobrir que há universidade.

O objetivo deste trabalho é apresentar um breve relato sobre a constituição das primeiras orquestras no mundo, no Brasil, as funções do regente, dos músicos e os possíveis modelos adotados pelas universidades, para então traçar considerações sobre a Orquestra Sinfônica da Universidade de São Paulo como uma poderosa ferramenta cultural a serviço da extensão universitária.

Para a realização deste artigo procedeu-se a uma pesquisa exploratória com base em revisão bibliográfica, tendo em vista a ausência de textos que apresentem o "estado da arte" sobre o assunto, conduzindo à necessidade da reunião dessas informações para que pudessem ser identificadas as relações entre universidade, cultura, extensão e uma orquestra sinfônica com as características da OSUSP.

\section{A ORIGEM DAS ORQUESTRAS SINFÔNICAS}

Entre as instituições criadas pela civilização ocidental com significativo papel na evolução cultural, merece destaque a orquestra sinfônica.

Na Grécia, durante o século V a.C., os espetáculos eram encenados em teatros ao ar livre, chamados anfiteatros. Orquestra era o nome dado ao espaço que se situava em frente à área principal de representação e que se destinava às evoluções do coro, que cantava e também dançava. Era ali que ficavam igualmente os instrumentistas. [2]

No início do século XVII, na Itália, começaram as execuções das primeiras óperas com a intenção de criar uma imitação dos dramas gregos. Dessa maneira, a palavra orchestra foi utilizada para descrever o espaço entre o palco e o público utilizado pelos instrumentistas. Com o tempo, o termo passou a designar o próprio grupo de músicos e seus instrumentos. Quanto ao termo sinfonia, deriva do grego synphone e foi utilizado desde a Idade Média para designar a música executada em conjunto. No século XVII este termo foi utilizado - assim como o termo abertura - para designar a peça instrumental introdutória de óperas, oratórios e cantatas.

Até o século XVII cabia ao diretor musical a escolha dos instrumentos, conforme a disponibilidade local, para a execução de uma obra. Os compositores raramente especificavam os instrumentos. $\mathrm{O}$ desenvolvimento da ópera influenciou decisivamente na constituição dos grupos instrumentais mais estáveis. Cláudio Monteverdi, na ópera L'Orfeo, indicou a lista de instrumentos que deveriam acompanhar o coro, os solistas e executar, a cada momento, as passagens instrumentais. Foi, dessa maneira, o primeiro 
compositor a definir os timbres de uma obra com orquestra, estabelecendo os instrumentos que comporiam o conjunto orquestral.

Num primeiro momento, as orquestras sinfônicas eram patrocinadas por verbas públicas e as filarmônicas por grupos privados, de amigos da música, mas, com o passar do tempo, essas designações passaram a significar igualmente conjuntos orquestrais de grande porte, em oposição às orquestras de câmara, formadas por poucos músicos ou sem todos os naipes instrumentais.

O limite e a variedade de instrumentos de uma orquestra têm mudado continuamente nos últimos quatro séculos e, na atualidade, leva em conta a combinação instrumental específica indicada pelo compositor.

A orquestra do séc. XX incorporou um grande número de instrumentos de percussão, incluindo vários de origem oriental ou "exóticos", usados entre outros por Debussy, Stravinsky e Bartók. A orquestra sinfônica atual é constituída segundo o modelo do final do séc. XIX, a formação típica sendo: 32 violinos, I2 violas, I2 violoncelos, 8 contrabaixos, 4 de cada um dos sopros de madeira (flauta, oboé, clarineta, fagote), 8 trompas, 4 trompetes, 3 trombones, tuba e percussão diversificada. Outras formações incluem a orquestra de câmara, criada como uma reação ao gigantismo da orquestra pós-romântica, a orquestra alterada para execução de obras de vanguarda, que explora os timbres por intermédio de sintetizadores; e a orquestra de instrumentos de época, destacando-se os conjuntos para execução de música barroca, clássica e do primeiro romantismo. [7]

As orquestras comportaram uma evolução histórica, dos pequenos conjuntos barrocos às grandes sinfônicas do romantismo tardio, que induziram não só ao acréscimo de instrumentos, mas também a um aumento em sua complexidade timbrística, harmônica e, sobretudo, administrativa. Segundo Bertero, "as orquestras adaptaram-se a públicos cambiantes, a novas partituras e compositores e aos novos espaços em que se vem fazendo música ao longo dos tempos" [3]. A evolução desses conjuntos instrumentais passa da intimidade das pequenas capelas e salões para as grandes salas de concerto erguidas a partir do final do século XIX onde a intimidade dá lugar à impessoalidade.
Carvalho aponta que:

[...] a evolução das obras para orquestra de grandes dimensões encontrou problemas de ordem prática para sua continuação. Altos custos de manutenção e de pessoal, além da exigência de palcos de dimensões excepcionais e auditórios proporcionalmente grandes, são fatores que corroboram para o enfraquecimento dessa prática. [5]

Constituindo um produto diferenciado e extremamente sofisticado, as orquestras foram assimiladas com mais facilidade nas regiões do mundo colonizadas por europeus. Na América Latina, com a mescla das culturas africana e indígena, as orquestras tiveram que partilhar o espaço musical.

O Collegium Musicum, de Frankfurt, data de I7II e é uma das instituições mais antigas a fundar um grupo sinfônico para a execução de música de concerto, seguido por Paris, com o Concerts Spirituels, de I725, e de Leipzig, com a Gewandhaus, de I743. Estes grupos não constituíram orquestras estáveis, mas utilizavam o sistema de contratação por temporada, de modo que "o número de músicos e a duração dos contratos dependiam do número de concertos executados" [5].

A título de exemplo, apresentamos no Quadro I (ver Anexo), um resumo com a data de fundação de algumas das mais antigas orquestras no mundo e no Brasil e, também, de algumas das mais renomadas sinfônicas da atualidade.

Palácios e igrejas possuíam conjuntos musicais anteriores ao cristianismo, formados por grupos de instrumentistas, mas cuja designação de orquestra sinfônica começa a fazer sentido apenas a partir da apresentação de concertos públicos, com grupos relativamente estáveis de músicos, que interpretavam sinfonias ou concertos escritos com base num naipe de cordas ao qual poderiam se somar instrumentos de sopro (madeiras e metais) e percussão (especialmente os tímpanos).

No século XVIII, o Brasil já possuía algumas orquestras, em Minas Gerais, pertencentes às irmandades religiosas, mas não podemos classificá-las como sinfônicas. A atuação destes grupos orquestrais estava voltada principalmente para o acompanhamento de coro e solistas em funções litúrgicas.

Analisando o Quadro 2 (ver Anexo), percebe-se que as universidades públicas brasileiras, em sua 
maioria, passaram a criar suas orquestras em torno dos anos I970, provavelmente acompanhando o estabelecimento de seus cursos de Música e sua consolidação como grandes universidades no contexto do ensino superior no país.

Uma orquestra deve se aprimorar constantemente através de ensaios e criação de repertório e, independentemente de seu tamanho ou vinculação a uma universidade, órgão estatal ou grupo empresarial, só pode prosperar se estiver constituída sobre alicerces artisticamente sólidos e que incluam a formação de público.

\section{O REGENTE E A DIREÇÃO DA ORQUESTRA}

A profissão do maestro é recente. Ele só se tornou necessário na medida em que os conjuntos aumentaram de tamanho e as partituras ficaram mais complexas. No passado, a regência era uma atividade masculina, especialmente por seu sentido de controle, poder e liderança de grupo e pelo gestual esperado do regente. Neste trabalho, os termos regente e maestro são usados como sinônimos, e em sua forma masculina, embora atualmente já seja significativo o número de mulheres regentes (maestrinas), da mesma maneira que boa parte dos instrumentistas das orquestras em todo o mundo é composto atualmente por mulheres (musicistas).

Orquestras sinfônicas foram monarquias absolutas a partir do pódio, compondo-se com modelos de gestão que reforçavam o autoritarismo de regentes e administradores. Nos Estados Unidos, o modelo vigente até a pouco tempo, e hoje em visível crise, era o de uma orquestra dirigida por um conselho que conseguia os fundos com os quais a orquestra se mantinha, oferecia generosas temporadas e contratava um maestro que acumulava as funções de regente titular e diretor artístico. [3]

Os maestros passam a ser compreendidos como profissionais com habilidade e competências específicas, diversas das dos músicos. Trata-se, entretanto, de talentos complementares e que não se hierarquizam [3].

Entre as principais qualificações de um maestro estão: o talento musical significativo, incluindo bom ouvido e técnica de regência apurada; a capacidade de concentração e estudo para assimilar as composições musicais; capacidade de gerir ensaios; linguagem corporal adequada ao desempenho artístico nas apresentações; capacidade de desenvolver ideias criativas de programação; conhecimento sobre intérpretes e solistas e suas áreas de especialização; capacidade para administrar conflitos e apoiar o bem-estar emocional dos músicos da orquestra; capacidade de adequar-se e auxiliar no aprimoramento das regras administrativas e de comunicação de um grupo orquestral.

Os primeiros líderes da orquestra eram designados simplesmente como maestros. Muitas orquestras, especialmente as americanas, passaram a utilizar, a partir de meados do século XX, o título de diretor musical para designar o maestro principal e líder artístico. Este diretor, no jargão americano, também é o principal foco da publicidade da orquestra e colabora para angariar fundos, constituindo uma espécie de face pública da orquestra. Muitas vezes, esse cargo incluiu o controle das execuções e gravações da orquestra, a contratação e demissão de músicos. Esse modelo vem perdendo força em nome de uma administração mais profissional, centrada em resultados menos identificados com a figura autoritária do maestro e mais adequados à partilha da gestão com os músicos da orquestra, o pessoal administrativo e o conselho de administração. Nas orquestras brasileiras, esta concepção tem sido utilizada com os rótulos diretor artístico e regente titular. Nas orquestras europeias, o mais comum é o título de condutor principal ou regente principal, designando o maestro que dirige a maioria dos concertos em uma temporada, diferenciando-o de um regente convidado, mas dando conta da limitação de seu poder.

As grandes orquestras no Brasil e no mundo têm caminhado no sentido de separar as funções da direção artística das do maestro, de modo a garantir que a personalidade artística do regente - ou dos regentes convidados -, seja considerada, mas sem impedir a orquestra de praticar uma evolução em suas temporadas e programações que levem em conta, de forma mais efetiva, os interesses reais do grupo sinfônico, do público e de seus apoiadores.

A maioria das orquestras possui também a figura do diretor administrativo, responsável por questões não artísticas, como o gerenciamento de contratos, a negociação de cachês, a reserva e administração dos espaços de concerto, a assessoria de imprensa, a negociação com patrocinadores e com conselhos gestores e, enfim, toda a infraestrutura de apoio às atividades da orquestra. 


\section{OS INSTRUMENTISTAS}

Os músicos de orquestra não possuem mais o perfil característico do passado, quando eram vistos apenas como capazes para executar seus instrumentos, sem uma cultura musical mais requintada. São, atualmente, profissionais altamente qualificados, com sólida formação que transcende os conhecimentos e habilidades técnicas de executantes de um instrumento.

Quando um músico entra para uma orquestra profissional, geralmente deixa de lado suas pretensões em seguir a carreira de solista. A rotina diária da orquestra costuma levar o músico a uma dedicação quase exclusiva, com a complementação de seu tempo e rendimentos financeiros com aulas particulares ou em escolas de música. $\mathrm{O}$ fato de ser aceito em uma orquestra demonstra que o músico possui requisitos fundamentais, como afinação, sonoridade, domínio rítmico etc. e que apresenta amadurecimento, especialmente sob o ponto de vista técnico, para enfrentar o repertório sinfônico de maior dificuldade.

Um músico de orquestra está exposto a grande desgaste psicológico, especialmente por depender de suas condições físicas para a execução de seu instrumento, por depender da interação sutil com os outros instrumentistas e por se apresentar publicamente de forma constante.

As comissões representantes de músicos das orquestras exercem papel significativo na reivindicação da melhoria nas condições de trabalho, no diálogo com regentes e administradores e, mais recentemente, têm participado mais ativamente na formulação de diretrizes artísticas e programação das sinfônicas brasileiras e estrangeiras.

\section{MODELOS DE ORQUESTRAS EM UNIVERSIDADES}

As orquestras da maioria das universidades, tanto no Brasil como no exterior, são vinculadas ao curso de Música e dirigidas pelo maestro/professor da cadeira de Prática de Orquestra; neste caso, o objetivo é a prática dos estudantes. Os professores de instrumentos podem participar voluntariamente dos ensaios e apresentações, muitas vezes restritas à universidade. Algumas universidades promovem a prática de receber solistas e maestros convidados, independente da área acadêmica. Elas promovem, desta maneira, possibilidades de maior integração entre os alunos e músicos profissionais, preparando-os de maneira mais eficaz para o mercado profissional. Exemplos deste tipo de orquestra são a Orquestra Sinfônica de Yale, nos Estados Unidos; a Orquestra Sinfônica da Liszt School de Weimar, na Alemanha; a Orquestra Sinfônica da Universidade Federal do Rio de Janeiro (OSUFRJ); a Orquestra Sinfônica da Universidade Federal de Minas Gerais (OSUFMG) e a Orquestra Sinfônica da Universidade de Campinas (OSU).

Outro modelo é o da orquestra profissional na universidade. Neste modelo há a necessidade de estrutura profissional, quadros efetivos de músicos e servidores administrativos e é comum a busca de fontes externas de financiamento. Geralmente, este tipo de orquestra tem uma atuação artística mais qualificada, apresenta temporadas de concertos públicos e não está vinculada ao curso de música, tendo maior autonomia e independência em sua atuação artística. São exemplos deste modelo, a Orquestra Filarmônica da Universidade Nacional Autônoma do México, a Orquestra Sinfônica Nacional da Universidade Federal Fluminense (OFF) e a Orquestra Sinfônica da Universidade de São Paulo (OSUSP), sobre a qual nos deteremos no próximo tópico.

\section{A ORQUESTRA SINFÔNICA DA UNIVERSIDADE DE SÃO PAULO (OSUSP)}

A Universidade de São Paulo é uma das principais universidades brasileiras, a que tem maior destaque internacional e que é reconhecida como paradigma significativo no ensino, na pesquisa, na cultura e extensão universitária e na gestão acadêmica.

Em I975, sob a direção artística e regência do renomado compositor paulista Camargo Guarnieri, a USP deu início às atividades da OSUSP tendo como objetivos principais, conforme Resolução CoCEx 5294/ 2006†: divulgar a música sinfônica e camerística, especialmente a brasileira e latino-americana, através de concertos destinados aos professores, alunos, funcionários, e comunidade em geral; promover concertos

$\dagger$ CoCEx: Conselho de Cultura e Extensão Universitária da Universidade de São Paulo. 
didáticos nos vários campi da Universidade; promover cursos e festivais para divulgar a cultura musical junto à comunidade em geral; promover o intercâmbio musical com universidades e demais instituições no Brasil e no exterior; promover estágios e concursos envolvendo jovens solistas, compositores e maestros e desenvolver, em acordo com o Departamento de Música da Escola de Comunicações e Artes (ECA) e com o CoralUSP, iniciativas de colaboração mútua.

Optou-se pela criação de uma orquestra com os músicos admitidos por concurso, como servidores da Universidade, sem vinculação com o Departamento de Música. O curso de Música da Escola de Comunicações e Artes teve início no ano de I97I, com o ingresso de estudantes dedicados ao piano, à composição, à regência, ao canto e aos instrumentos de orquestra. $\mathrm{O}$ pequeno número de alunos de instrumentos de orquestra na USP certamente influenciou a criação de um grupo profissional independente, além da necessidade de implantação, com brevidade, de um grupo musical à altura do status acadêmico que a USP já desfrutava nos anos 1970.

Desde a sua fundação, inicialmente como uma orquestra composta apenas por instrumentos de corda, a OSUSP tem buscado formar uma base artística sólida, incluindo em sua rotina ensaios diários e apresentações regulares para o público da USP e para o público externo, contando com a participação de solistas e regentes convidados, alguns considerados entre os de maior destaque no cenário internacional, e tem reforçado seu quadro de músicos efetivos - cotados entre os melhores músicos do cenário nacional - com a contratação ocasional de vários instrumentistas profissionais e jovens instrumentistas e alunos em ascensão para poder completar seus quadros e executar o repertório sinfônico destinado às grandes formações orquestrais.

Para atingir seus objetivos, a OSUSP apresenta uma série de concertos anuais na Sala São Paulo com a participação de solistas e regentes de projeção internacional e possibilita a subscrição de assinaturas.

Como uma orquestra inserida na Universidade de São Paulo, a OSUSP não é mera reprodutora de linguagem, mas promove condições para perceber avanços da sociedade e auxiliar na formação de cidadãos capazes da fruição da arte, enfrentando o grande desafio de preservar a especificidade de seu métier mesmo com a mercantilização da cultura.

A OSUSP não se coíbe do desempenho público, dos grandes concertos nas principais salas da cidade, mas não descuida de sua função fundamental, propiciando a formação do público, estimulando a educação, a formação do gosto e a cidadania em sentido amplo.

Nunca é redundante lembrar que o desconhecimento da própria herança cultural aliena os cidadãos da condição de participar de forma consciente da vida do seu país; na ausência de um público apreciador das artes nas suas mais variadas expressões não há efetiva cidadania; tampouco poderá existir uma sociedade realmente desenvolvida. A Orquestra Sinfônica da Universidade de São Paulo preserva, desse modo, a sua índole natural, por contribuir com a tarefa inexcedível de oferecer aos seus espectadores a possibilidade de conhecer e apropriar-se de um conjunto cuidadosamente selecionado, executado por artistas exímios e cônscios do atributo delicado do trabalho a que se dedicam. [...] A comunidade da USP se reconhece na imagem refletida por sua orquestra. [I]

Acompanhando a tendência geral identificada nas grandes sinfônicas internacionais, a OSUSP está buscando um modelo menos centrado na figura do regente, não por considerá-lo uma figura menor ou desnecessária, mas para estar mais próxima dos anseios gerais da comunidade artística da orquestra e da Universidade, incluindo aqui os departamentos de Música da Universidade. Afinal, a Sinfônica da USP deve desempenhar o seu papel em conformidade com os princípios que regem a Universidade, levando a cultura musical de excelência e o nome da Universidade em suas atividades baseadas no ensino e na pesquisa, desenvolvendo uma identidade que a diferencie e projete em relação às demais orquestras, especialmente da cidade de São Paulo. Neste sentido, vale ressaltar que:

[...] se empresas podem perecer porque se apegam a produtos, mercados, tecnologias, formatos organizacionais e modos de gestão que não mais funcionam, orquestras igualmente padecem exatamente dos mesmos riscos. Orquestras podem apegar-se a repertórios que, por mais consagrados que sejam, acabam gerando um certo efeito de monotonia e repetição. [3] 
É altamente recomendável o aumento do quadro de músicos efetivos da OSUSP para que ela possa ser realmente uma orquestra sinfônica - como foi imaginada desde a sua fundação, em 1975 -, passando dos atuais quarenta músicos para um total não inferior a setenta, e promova a execução de obras significativas do repertório brasileiro e internacional com um grupo mais estável, com a participação mínima de músicos autônomos, executando obras tradicionais, música nova, estimulando compositores, intérpretes, regentes, alunos e, especialmente, o grande público que ela atinge atualmenteł e que pretende ver aumentar nos próximos anos com novas temporadas que incluam mais concertos anuais, tanto fora como dentro da Universidade.

A OSUSP apresenta todos os anos uma série de concertos didáticos, voltados ao público infantil. Os concertos contam com a participação de atores e de crianças solistas e apresentam um roteiro que privilegia informações sobre os instrumentos, sobre os grupos formadores da orquestra e sobre as funções do regente. Concebidos de forma lúdica, com repertório de fácil assimilação, estes concertos são uma importante ferramenta para a aproximação do público infantil e influem na formação do gosto e na preparação desse público para a melhor apreciação das obras sinfônicas\$.

\section{CONSIDERAÇÕES FINAIS}

O Brasil formou tardiamente suas universidades e elas foram criadas para fazer uma ponte com a sociedade, possibilitando uma formação cidadã, o diálogo com os jovens e a abertura às novidades no ensino, na pesquisa e na cultura.

A Universidade de São Paulo é um ambiente propício para uma orquestra sinfônica profissional e deve utilizá-la como forma de desenvolver e fortalecer a cultura erudita instrumental no país. O papel educacional de uma orquestra universitária é fundamental para que ela cumpra sua missão na promoção da cultura e extensão visando particularmente às novas gerações. O público deve ser informado para compreender

\footnotetext{
$\ddagger$ No ano de 20II, o público total estimado da OSUSP foi de 28.075 pessoas.

$\S$ No ano de 20II, o público infantil total estimado da OSUSP foi de II. 686 crianças.
}

o que é executado. As orquestras são "como todas as demais organizações, marcadas pelo tempo e pelo ambiente que as circunda. Como empresas, elas comportam divisões de tarefas, níveis de autoridade, conflitos entre egos e papeis e evoluem no tempo" [3].

Fomentar o gosto pela música, passar o legado de grandes mestres universais, apresentar novas propostas e estilos e alcançar a comunidade intra e extramuros da universidade, encantando com a arte da orquestra, resumem algumas das ações da área de cultura e extensão que a OSUSP, desde a sua fundação, vem desempenhando e deve aprimorar na Universidade de São Paulo, demonstrando que a herança cultural, a criação e inovação musical têm sido pilares para que a orquestra seja um componente vital da ligação da academia com a sociedade.

\section{REFERÊNCIAS BIBLIOGRÁFICAS}

[I] ARRUDA, Maria Arminda do Nascimento. OSUSP: Temporada 20II. In: Orquestra Sinfônica da USP: Temporada 20II. São Paulo: USP, 20II. Não paginado. I folder. Texto de apresentação da temporada de concertos da Orquestra Sinfônica da Universidade de São Paulo.

[2] BENNETT, Roy. Instrumentos da orquestra. Rio de Janeiro: Zahar, I985. p. 9.

[3] BERTERO, Carlos Osmar. Orquestras Sinfônicas: uma metáfora revisitada. Revista de Administração de Empresas, v. 4I, n. 3, p. 84-88, jul.-set. 200 I.

[4] BUARQUE, Cristovam. Na fronteira do futuro: o projeto da UnB. Brasília: UnB, I989. Io8 p.

[5] CARVALHO, Luis Fabricio Cirillo de. Orquestra Sinfônica Universitária: modelos e alternativa de implementação em universidades públicas. 2005. IOI $\mathrm{f}$. Dissertação (Mestrado em Música) - Instituto de Artes, Universidade Estadual de Campinas, Campinas, 2005.

[6] FINGER, Almeri Paulo. Universidade: organização, planejamento e gestão. Florianópolis: UFSC; CPGA; NUPEAU, i988. p. I3.

[7] SADIE, Stanley (Ed.). Dicionário Grove de Música. Rio de Janeiro: Zahar, I994 · p. 686. 


\section{ANEXO}

\section{QUADRO 1}

Data de fundação de algumas orquestras no mundo e no Brasil*

\begin{tabular}{|c|c|c|}
\hline ORQUESTRA & PAís & $\begin{array}{l}\text { ANO DE } \\
\text { FUNDAÇÃO }\end{array}$ \\
\hline (Staatskapelle Dresden) & Alemanha & $(\mathrm{I} 548)$ \\
\hline Collegium Musicum de Frankfurt & Alemanha & I7II \\
\hline Concerts Spirituels de Paris & França & I725 \\
\hline $\begin{array}{l}\text { (Sociedade de Concertos Grossos) } \\
\text { Orquestra Gewandhaus de Leipzig }\end{array}$ & Alemanha & $\begin{array}{c}(\mathrm{I} 743) \\
\mathrm{I} 78 \mathrm{I}\end{array}$ \\
\hline Orquestra Lira Sanjoanense & Brasil & I776 \\
\hline Orquestra Ribeiro Bastos & Brasil & I790 \\
\hline Orquestra Filarmônica de Berlim & Alemanha & I882 \\
\hline Orquestra Filarmônica de Viena & Áustria & I 842 \\
\hline Orquestra Filarmônica de Nova York & Estados Unidos & I842 \\
\hline Orquestra Real do Concertgebouw & Holanda & I888 \\
\hline Orquestra Universitária de Princeton & Estados Unidos & I896 \\
\hline Orquestra Universitária Columbia & Estados Unidos & I896 \\
\hline Orquestra Sinfônica de Chicago & Estados Unidos & I897 \\
\hline Orquestra Sinfônica de Londres & Inglaterra & I904 \\
\hline Orquestra de Gleveland & Estados Unidos & I9I8 \\
\hline Orquestra Filarmônica de Los Angeles & Estados Unidos & I9I9 \\
\hline $\begin{array}{l}\text { Orquestra Sinfônica do Theatro Municipal } \\
\text { do Rio de Janeiro }\end{array}$ & Brasil & I93I \\
\hline $\begin{array}{l}\text { (Sociedade de Concertos Sinfônicos de São Paulo) } \\
\text { Orquestra Sinfônica Municipal de São Paulo }\end{array}$ & Brasil & $\begin{array}{l}(\text { I92I }) \\
\text { I936 }\end{array}$ \\
\hline Orquestra Sinfônica Brasileira (OSB) & Brasil & I940 \\
\hline Orquestra Sinfônica da Rádio da Baviera & Alemanha & I949 \\
\hline Orquestra Sinfônica do Estado de São Paulo (OSESP) & Brasil & I954 \\
\hline $\begin{array}{l}\text { (Orquestra Sinfônica Campineira) } \\
\text { Orquestra Sinfônica Municipal de Campinas }\end{array}$ & Brasil & $\begin{array}{l}(\text { I929) } \\
\text { I974 }\end{array}$ \\
\hline Orquestra do Festival de Budapeste & Hungria & I983 \\
\hline
\end{tabular}

*Os nomes e datas entre parêntesis indicam os primórdios do grupo, antes de sua afirmação como orquestras. 
QUADRO 2

Data de fundação de algumas orquestras de universidades brasileiras

\begin{tabular}{lcc}
\hline ORquestra & ESTADO & $\begin{array}{c}\text { ANO DE } \\
\text { FUNDAÇO }\end{array}$ \\
\hline $\begin{array}{l}\text { Orquestra Sinfônica da Universidade Federal do } \\
\text { Rio de Janeiro (OSUFRJ) }\end{array}$ & Rio de Janeiro & I924 \\
\hline $\begin{array}{l}\text { Orquestra Sinfônica Nacional da Universidade } \\
\text { Federal Fluminense (OFF) }\end{array}$ & Rio de Janeiro & I972 \\
\hline $\begin{array}{l}\text { Orquestra Sinfônica da Universidade Federal de } \\
\text { Minas Gerais (OSUFMG) }\end{array}$ & Minas Gerais & I975 \\
\hline $\begin{array}{l}\text { Orquestra Sinfônica da Universidade de São Paulo } \\
\text { (OSUSP) }\end{array}$ & São Paulo & I982 \\
\hline $\begin{array}{l}\text { Orquestra Sinfônica da Universidade de Campinas } \\
\text { (OSUNICAMP) }\end{array}$ & São Paulo & I9to \\
\hline
\end{tabular}

